\title{
Mediación en casos de violencia de género
}

\section{Mediation in cases of gender violence}

Gema Vallejo Pérez. ${ }^{1}$

Resumen: La Mediación en los casos de violencia de género es muy discutida. Prohibida por ley, que excluye expresamente esta mediación, empiezan sin embargo a surgir las voces en la doctrina que abogan por la posibilidad de aplicar la mediación en caso de violencia de género. Para ello, a través de la casuística, se valoró la compatibilidad de la mediación con los protocolos de actuación en los juzgados de violencia sobre la mujer.

Palabras claves: violencia, mujer, legislación, protocolo, mediación, voluntariedad, obligatoriedad.

\begin{abstract}
Mediation in cases of gender violence is highly discussed. Prohibited by law, which expressly excludes this mediation, nonetheless begin to emerge the voices in the doctrine that advocate the possibility of applying mediation in case of gender violence.. For this, through the casuistry, it was assessed the compatibility of mediation with the protocols of action in the courts of violence against women.
\end{abstract}

Keywords: violence, woman, legislation, protocol, mediation, voluntary, compulsory.

\footnotetext{
${ }^{1}$ Universidad de León, España, Departamento De Derecho Privado y De La Empresa, PROFESORA
} ADSOCIADA. 


\section{LA VIOLENCIA DE GÉNERO EN ESPAÑA}

La utilización de la expresión "Violencia de género" es relativamente joven, lo que da cuenta del tardío reconocimiento de una realidad tan dura y antigua como es el maltrato dirigido hacia las mujeres. Además, la resistencia a reconocer que la violencia de género, no es una cuestión biológica, sino de género, consecuencia de la tradicional sociedad de estructura patriarcalque no ayuda a la lucha contra esta discriminación intemporal $^{2}$.

Estamos ante un fenómeno complejo, que necesita para una mejor comprensión la articulación de una serie de violencias, como la violencia física, la violencia estructural, la violencia simbólica ${ }^{3}$, o la violencia cultural para poder ser comprendida en su conjunto como un círculo peligroso, que debe ser minuciosamente analizado para poder combatirlo adecuadamente.

Estamos ante un problema global y de graves dimensiones, que requiere de una definición clara, única, inequívoca y universal para que ninguna sociedad pueda defender su posición de violencia contra las mujeres amparándose en la vaguedad de la regulación de la violencia de género o en su propia concepción ${ }^{4}$.

${ }^{2}$ Cfr. MAQUEDA ABRAU, M.L., La violencia de género entre el concepto jurídico y la realidad social, en Revista Electrónica de Ciencia Penal y Criminología, 08-02, 2006, p. 02- 2, en donde añade: "Se trata de una variable teórica esencial para comprender que no es la diferencia entre sexos la razón del antagonismo, que no nos hallamos ante una forma de violencia individual que se ejerce en el ámbito familiar o de pareja por quien ostenta una posición de superioridad física (hombre) sobre el sexo más débil (mujer), sino que es consecuencia de una situación de discriminación intemporal que tiene su origen en una estructura social de naturaleza patriarcal. El género, se constituye así en el resultado de un proceso de construcción social mediante el que se adjudican simbólicamente las expectativas y valores que cada cultura atribuye a sus varones y mujeres".

3 PLAZA VELASCO, M., Sobre el concepto de violencia de género. Violencia simbólica, lenguaje, representación en Extravío. Revista Electrónica de Literatura Comparada, 2, 2007, p. 135, en donde destaca que la violencia simbólica ejercida de forma suave e invisible en los cuerpos, nos permite acercarnos todavía más al concepto de violencia de género en toda "su complejidad y amplitud, porque nos sitúa en el problema de la formación de la identidad. Los mecanismos de poder no sólo intervienen desde el exterior del sujeto, sino desde su propio interior, porque son estas relaciones de poder las que constituyen al sujeto, lo forman".

${ }^{4}$ Vid. al respecto, ENGLE MERRY, S., Gender violence. A Cultural Perspective, West Sussex, 2009 , p. 11, en donde señala que no existe una explicación universal para la violencia de género, y que ni siquiera podemos dar por supuesto que se prodigue con mayor intensidad en sociedades rurales que en espacios urbanos, porque no es cierto. A continuación, expone su propio concepto de violencia de género: "In this book I define gender violence as violence whose meaning depends on the gendered identities of the parties". 
Si hablamos de categorías, podemos dividir la violencia de género en estas tres categorías $^{5}$ : violencia sexual, violencia física y violencia psicológica ${ }^{6}$, siendo esta última la más difícil de concretar porque no se refiere solamente a los comentarios despectivos o a las humillaciones continuas, sino también a la desaprobación general de todos los actos de la mujer, así como el control absoluto de cada una de sus acciones.

La definición de "violencia de género" más comúnmente aceptada y valorada la encontramos en la Declaración de las Naciones Unidas sobre la Eliminación de la Violencia contra la Mujer de 1993. En la referida Declaración se da un concepto amplio de violencia, ya que abarca tanto el daño físico y psíquico como la privación de libertad, las coacciones y las vejaciones, pues dice que será un acto de violencia de género aquel "que resulte o pueda resultar en sufrimiento físico, sexual o daño psicológico o

${ }^{5}$ NOYA FERREIRO, L.La protección de la mujer víctima de violencia de género en Galicia: regulación procesal, en Estudios penales y criminológicos, $\mathrm{n}^{\circ} 28,2008$, p. 211, en donde sigue la clasificación del Consejo de Europa, sin duda más prolífica en cuanto a la categorización de las diferentes violencias posibles, pero que nosotros hemos considerado que se pueden subsumir en tres, como acabamos de ver. De este modo, los diferentes tipos de violencia serían: "Violencia física: en la que se incluyen todo tipo de agresiones corporales (empujones, golpes, ataques con armas, mordeduras, quemaduras, estrangulamientos, mutilaciones, etc...). Violencia sexual: que comprende cualquier actividad sexual no consentida (visionado o participación forzada en pornografía, relaciones sexuales obligadas, tráfico y explotación en la industria del sexo, etc...). Violencia psicológica: concepto amplio que admite múltiples modalidades de agresión intelectual o moral (amenazas, aislamiento, desprecio, intimidación e insultos en público, etc...).Violencia económica: entendida como desigualdad en el acceso a los recursos compartidos (negar el acceso al dinero, impedir el acceso a un puesto de trabajo, a la educación etc...). Violencia estructural: término íntimamente relacionado con el de violencia económica, pero que incluye barreras invisibles e intangibles contra la realización de las opciones potenciales de los derechos básicos de las personas. Se sustenta la existencia de obstáculos firmemente arraigados y que se reproducen diariamente en el tejido social (por ejemplo, las relaciones de poder que generan y legitiman la desigualdad). Violencia espiritual: concepto comprensivo de aquellas conductas que consisten en obligar a otra persona a aceptar un sistema de creencias cultural o religioso determinado, o dirigidas a erosionar o destruir las creencias de otro a través del ridículo o del castigo".

${ }^{6}$ ALCÁZAR CÓRCOLES, M.A./ GÓMEZ-JARABO, G., Aspectos psicológicos de la violencia de género. Una propuesta de intervención, en Psicopatología Clínica, Legal y Forense, Vol.1, n 2, 2001, p. 35: "La violencia psicológica es cualquier acto o conducta intencionada que produce desvalorizaciones, sufrimientos o agresión psicológica a la mujer. Puede ser a través de insultos, vejaciones, crueldad mental, gritos, desprecio, intolerancia, humillación en público, castigo, dar muestra de desafecto, amenaza de abandono, subestimar... Es frecuente que comportamientos de maltrato psicológico sean socialmente aceptados dentro de los límites de la "normalidad". Algunos hombres no golpean físicamente a sus compañeras, pero las hacen víctimas cargándolas de reproches continuos y amenazas, lo cual las hace mantenerse en un estado de angustia y destruye su equilibrio psicológico. Este tipo de violencia conduce sistemáticamente a la depresión y a veces al suicidio". 
sufrimiento a la mujer, incluidas las amenazas de tales actos, la coacción o la privación arbitraria de la libertad, ya sea que ocurra en público o en la vida privada"7.

Lo que pone de relieve esta definición de violencia de género es que se trata de una violencia que sufren las mujeres por el simple hecho de serlo, y que se puede manifestar tanto en los malos tratos de la pareja, como agresiones físicas o sexuales de extraños, mutilación genital, infanticidios femeninos, etc.

En definitiva, no es más que la plasmación de la enorme desigualdad y del sometimiento en el que viven las mujeres en el mundo, presente en diversos ámbitos, con múltiples formas y en distintos grados de intensidad. Constituye un atentado a los Derechos Fundamentales recogidos tanto en las normas nacionales como internacionales: el derecho a la vida e integridad física, el derecho a la seguridad y el derecho a la libertad, a la dignidad y a la no discriminación; cuya vulneración es un lastre para el desarrollo de una sociedad democrática, que no se puede quedar muda ante situaciones en que la mujer, desgraciadamente, acaba pagando con su vida la inacción de los poderes públicos ${ }^{8}$.

La Organización de Naciones Unidas en la IV Conferencia Mundial de 1995 entendió que: la violencia contra las mujeres es incompatible con la igualdad y el desarrollo de una sociedad en paz, a la vez que suponía una violación de los derechos humanos y las libertades fundamentales ${ }^{9}$.

Por atentar contra bienes y valores tan superiores, la violencia de género no es un problema privado, sino que, afecta al orden público y a la paz social y ello ha hecho que a partir de las mencionadas Declaraciones de Naciones Unidas, desde otros ámbitos geográficos se haya ido legislando para erradicar esta lacra social ${ }^{10}$.

\footnotetext{
7 Naciones Unidas Derechos Humanos, Oficina del Alto Comisionado Resolución de la Asamblea General Resolución 48/104. En su artículo 2..Disponible en: http://www.ohchr.org/SP/ProfessionalInterest/Pages/ViolenceAgainstWomen.aspx.

${ }^{8}$ Recomendación General no 2, sexto periodo de sesiones, 1987. "El Comité para la eliminación de la discriminación contra la mujer".

${ }^{9}$ La Organización de Naciones Unidas en la IV Conferencia Mundial de 1995.

${ }^{10}$ Así, podemos citar, además de las ya mencionadas Declaraciones de Naciones Unidas, los siguientes normas y tratados de los que es parte España: Convención sobre la eliminación de todas las
} 
Por lo que respecta a España, esta materia está regulada en la Ley Orgánica 1/2004, de 28 de diciembre, de Medidas de Protección Integral contra la Violencia de Género (BOE núm. 313 de 29 de diciembre de 2004), en la Ley Orgánica 3/2007, de 22 de marzo, para la igualdad efectiva de mujeres y hombres ${ }^{11}$ y en el Real Decreto - Ley 9/2018 de 3 de agosto, de medidas urgentes para el desarrollo del Pacto de Estado contra la violencia de Género ${ }^{12}$.

formas de discriminación sobre la mujer de 1979; las Resoluciones de la última Cumbre Internacional sobre la Mujer celebrada en Pekín en septiembre de 1995; la Resolución WHA49.25 de la Asamblea Mundial de la Salud declarando la violencia como problema prioritario de salud pública proclamada en 1996 por la OMS; el informe del Parlamento Europeo de julio de 1997; la Resolución de la Comisión de Derechos Humanos de Naciones Unidas de 1997; y la Declaración de 1999 como Año Europeo de Lucha Contra la Violencia de Género, entre otros; la Decisión n. ${ }^{\circ}$ 803/2004/CE del Parlamento Europeo, por la que se aprueba un programa de acción comunitario (2004-2008) para prevenir y combatir la violencia ejercida sobre la infancia, los jóvenes y las mujeres y proteger a las víctimas y grupos de riesgo (programa Daphne II), ha fijado la posición y estrategia de los representantes de la ciudadanía de la Unión al respecto; Recogido en la Exposición de Motivos de la Ley 1/2004 de 28 de diciembre.

Convenio del Consejo de Europa sobre prevención y lucha contra la violencia contra la mujer y la violencia doméstica, Convenio de Estambul, hecho en Estambul el 11 de mayo de 2011, (BOE de 6 de junio de 2014) fue ratificado por España y ha entrado en vigor en agosto de 2014: Directiva 2011/99/UE sobre la Orden Europea de Protección; Directiva 2012/29/UE del Parlamento Europeo y del Consejo de 25 de octubre de 2012 por la que se establecen normas mínimas sobre los derechos, el apoyo y la protección de las víctimas de delitos , Directiva 2011/36/UE del Parlamento Europeo y del Consejo de 5 de abril 2011, relativa a la prevención y la lucha contra la trata de seres humanos y a la protección de las víctimas. Portal de la Unión Europea. Disponible en:. https://e-justice.europa.eu/content_gender_equality312-es.do.

11Anteriores a la Ley Orgánica 1/2004, de 28 de diciembre de medidas de protección integral contra la violencia de género: La Ley 35/1995, de 11 de diciembre de ayudas y asistencia a las víctimas de delitos violen- tos y contra la libertad sexual. La Ley 27/2003, de 31 de julio, reguladora de la Orden de protección de las víctimas de la violencia doméstica. La Ley Orgánica 14/1999, de 9 de junio, de modificación del Código Penal de 1995, en materia de protección a las víctimas de malos y de la Ley de Enjuiciamiento Criminal. La Ley Orgánica 19/1994, de 23 de diciembre, de protección a testigos y peritos en causas criminales. La Ley 38/1998, de 27 de noviembre, por la que se modifica la composición de la Comisión Nacional de Ayuda y Asistencia a las Víctimas de Delitos Violentos y contra la libertad sexual.

${ }^{12}$ Abogacía Española,El Consejo de Ministros ha aprobado el Real Decreto-leyde medidas urgentes para el desarrollo del Pacto de Estado contra la Violencia de Género, que modifica la Ley de Bases del Régimen Local, la Ley de Medidas de Protección Integral contra la Violencia de Género y el Código Civil. (pägina web). Disponible en: https:/www.abogacia.es/2018/08/06/el-gobierno-aprueba-elreal-decreto-ley-para-desarrollar-el-pacto-de-estado-contra-la-violencia-de-genero/.

"Estas modificaciones devuelven a los Ayuntamientos las competencias en esta materia.También fortalecen la tutela judicial, el acceso a la justicia y a los recursos de asistencia a las víctimas de violencia de género. Igualmente, se recoge que la confirmación de las situaciones de violencia de género se amplíe más allá de la sentencia o resolución judicial. Con esta iniciativa se da cumplimiento al Convenio de Estambulen lo que se refiere a prevención y diligencia debida ante casos de violencia de género.

Tras la Conferencia Sectorial de Igualdad celebrada el pasado 31 de julio, una de las medidas más urgentes para el cumplimiento del Pacto de Estado es ladevolución de competencias en la materia a la Administración local,por ser la más cercana a las víctimas. La promoción de la igualdad y la lucha contra la violencia de género entrarán a formar parte del catálogo de competencias propias gracias a la modificación de la Ley Reguladora de las Bases del Régimen Local.Asimismo, los fondos destinados a 
Tal como se recoge en la Exposición de Motivos II de la Ley Orgánica 1/2004, de 28 de diciembre, de Medidas de Protección Integral contra la Violencia de Genero hubo con anterioridad "en el Derecho Español avances legislativos en materia de lucha contra la violencia de género, tales como la Ley Orgánica 11/2003, de 29 de septiembre, de Medidas Concretas en Materia de Seguridad Ciudadana, Violencia Doméstica e Integración Social de los Extranjeros; la Ley Orgánica 15/2003, de 25 de noviembre, por la que se modifica la Ley Orgánica 10/1995, de 23 de noviembre, del Código Penal, o la Ley 27/2003, de 31 de julio, reguladora de la Orden de Protección de las Víctimas de la Violencia Doméstica; además de las leyes aprobadas por diversas Comunidades Autónomas, dentro de su ámbito competencial. Todas ellas han incidido en distintos ámbitos civiles, penales, sociales o educativos a través de sus respectivas normativas".

los programas dirigidos a erradicar la violencia de género para los Ayuntamientos-20 millones en el presente ejercicio y 40 millones de euros en 2019- se distribuirán vía transferencia finalista y directa, o a través de otras Entidades Locales.

La protección de los menores constituye uno de los ejes más importantes del Pacto de Estado. Por ello, el Real Decreto-ley incluye una modificación en el artículo 156 de Código Civil para que la atención y asistencia psicológica quede fuera del catálogo de actos que requieren una decisión común en la patria potestad, cuando cualquiera de los progenitores esté acusado en un proceso penal por atentar contra la vida, la integridad física, la libertad, la integridad moral o la libertad e indemnidad sexual del otro progenitor o de los hijos e hijas de ambos.

Por otro lado, la reforma de la Ley Orgánica 1/2004, de 28 de diciembre, de Medidas de Protección integral contra la Violencia de Género aprobada fortalece la tutela judicial para mejorar la participación de la víctima en el proceso penal ,con la designación urgente de abogados y procuradores de oficio en los procedimientos que aseguren la inmediata presencia para la defensa y representación de las víctimas. Además, la víctima podrá personarse como acusación particular en cualquier fase del procedimiento.

En relación con las ayudas reguladas en el artículo 27 de la Ley 1/2004, de 28 de diciembre, el Real Decreto-ley posibilita que dichas ayudas sean compatibles con otras de carácter autonómico o local.

Por último, y en línea con el artículo 18.3 del Convenio de Consejo de Europa que exige no subordinar la protección de las víctimas de violencia de género al ejercicio de acciones legales o declaración contra el autor, el Real Decreto-ley modifica la Ley integral para ampliar los mecanismos de acreditación de las situaciones de violencia de género. En este sentido, el reconocimiento de los derechos de las víctimas se podrá acreditar por el informe del Ministerio Fiscal, de los servicios sociales, de los servicios especializados o de los servicios de acogida destinados a víctimas de violencia de género. El Gobierno y las Comunidades Autónomas, en el marco de la Conferencia Sectorial,diseñarán de común acuerdo, los procedimientos básicos que permitan poner en marcha dicha acreditación". 
La Ley Orgánica $1 / 2004^{13}$, de 28 de diciembre, de Medidas de Protección Integral contra la Violencia de Género, al establecer y definir la violencia de genero dice en su articulado:

Artículo 1: Objeto de la Ley

“1. La presente Ley tiene por objeto actuar contra la violencia que, como manifestación de la discriminación, la situación de desigualdad y las relaciones de poder de los hombres sobre las mujeres, se ejerce sobre éstas por parte de quienes sean o hayan sido sus cónyuges o de quienes estén o hayan estado ligados a ellas por relaciones similares de afectividad, aun sin convivencia.

2. Por esta ley se establecen medidas de protección integral cuya finalidad es prevenir, sancionar y erradicar esta violencia y prestar asistencia a las mujeres, a sus hijos menores y a los menores sujetos a su tutela, o guarda y custodia, víctimas de esta violencia.

3. La violencia de género a que se refiere la presente Ley comprende todo acto de violencia física y psicológica, incluidas las agresiones a la libertad sexual, las amenazas, las coacciones o la privación arbitraria de libertad"

La importancia de los bienes protegidos ha hecho que a la hora de legislar contra la violencia de género, esta materia haya entrado plenamente dentro del ius puniendi del Estado, de manera que no se ha dejado resquicio a la intervención de otros medios alternativos para la solución de conflictos, y veda de manera expresa la mediación para estos supuestos ${ }^{14}$.

A mayor abundamiento, la regulación autonómica ha entrado a regular esta materia, como por ejemplo sucede con la ley 11/2007 de Violencia de Género de

${ }^{13}$ FARALDO CABANAS, P., Razones para la introducción de la perspectiva de género en Derecho penal a través de la Ley Orgánica 1/2004, de 28 de diciembre, sobre medidas de protección integral contra la violencia de género, en Revista Penal, 17, 2006,p. 92: "La LO 1/2004 no es la mejor de las posibles, pero sí pone en el candelero un tema fundamental de nuestro tiempo, como es la necesidad de superar la igualdad formal en favor de políticas activas que favorezcan la igualdad de hecho. y probablemente sólo por ello merezca ya un tímido aplauso".

${ }^{14}$ Así, el artículo 44. 4 de la Ley Orgánica 1/2004, de 28 de diciembre, de Medidas de Protección Integral contra la Violencia de Género, veda expresamente la aplicación de estos procesos. 
Galicia $^{15}$, cuando modifica la ley 4/2001, de 31 de mayo, reguladora de la mediación familiar $^{16}$ en su Disposición Adicional Primera. Así, añade un nuevo punto 4 en el artículo 8, con la siguiente redacción:

“4. Se interrumpirá, o en su caso no se iniciará, cualquier proceso de mediación familiar cuando en él esté implicada una mujer que sufriera o sufra violencia de género" $"$.

Sin embargo, hasta el momento, la criminalización y judicialización no han conseguido disminuir notablemente los casos de violencia de género, como vemos por las estadísticas del Consejo General del Poder Judicial ${ }^{18}$. La realidad constata que debemos combatir la lacra de la violencia de género con todas las armas legales posibles, sabiendo que se necesita tiempo y un esfuerzo denodado a la hora de conseguir reducir las cifras de tan execrable delito.

${ }^{15}$ NOYA FERREIRO, L. La protección de la mujer víctima de violencia de género en Galicia: regulación procesal, en Estudios penales y criminológicos, n. 28, 2008, p. 214: “Como señala su Exposición de Motivos, articula un marco normativo propio y completo en esta materia, que haga de la prevención el pilar básico de la acción administrativa, y que facilite un adecuado apoyo a la lucha social contra la violencia de género. Con la presente Ley se pretende dotar a los poderes públicos y a la sociedad gallega de un instrumento apropiado para prever, tratar y erradicar la violencia de género y, al fin, conseguir una verdadera realización del principio de igualdad".

${ }^{16}$ BRAVO BOSCH, M. J., Sobre el nuevo real decreto-ley 5/2012 y la mediación familiar, en Revista General de Derecho Romano 18, www. iustel.com, 2012, p. 20-21.

${ }^{17}$ Cfr. BRAVO BOSCH, M. J., La mediación familiar en el estado de las autonomías, en La mediación en las controversias civiles y mercantiles, Iglesias Canle, I. (dir.), Valencia 2014, Ed. Tirant lo Blanch, p. 148.

${ }^{18}$ Consejo General del Poder Judicial,(Página web), Observatorio contra la violencia doméstica y de género, pág. 38. Disponible en http://www.poderjudicial.es/cgpj/es/Poder-Judicial/En-Portada/En-eltercer-trimestre-del-ano-aumentaron-las-denuncias-por-violencia-de-genero-y-las-condenas-a-losmaltratadores 


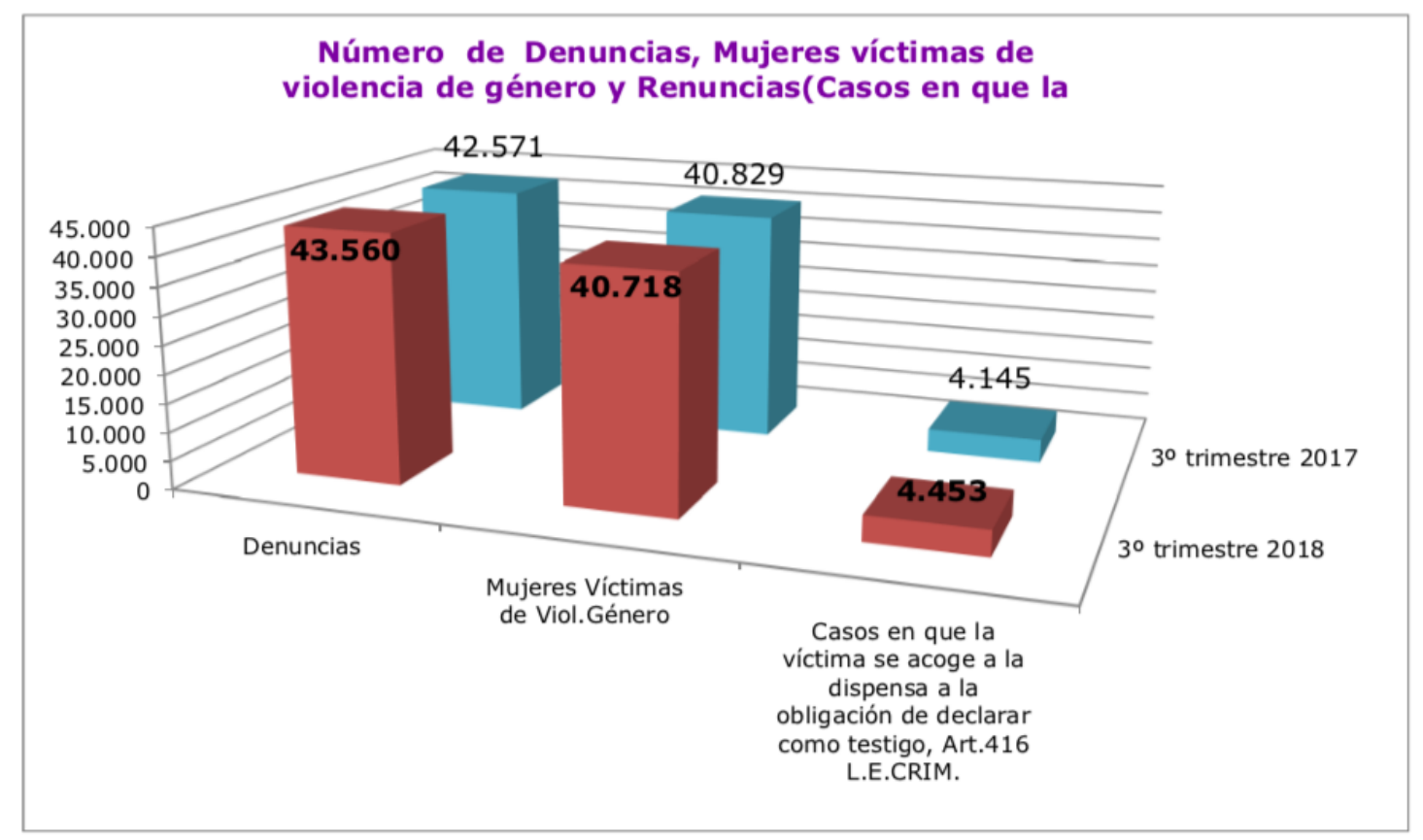

Lo que hace que nos planteemos dos preguntas: ¿Caben otros métodos alternativos?; ¿Qué soluciones han adoptado los países de la Unión Europea?

La Decisión Marco del Consejo de la Unión Europea relativa al Estatuto de la Víctima en el proceso penal de 15 de marzo, dispone en su artículo 10 que, "Los Estados miembros procurarán impulsar la mediación en las causas penales para las infracciones que a su juicio se presten a este tipo de medida. Los Estados miembros velarán por que pueda tomarse en consideración todo acuerdo entre víctima e inculpado que se haya alcanzado con ocasión de la mediación en las causas penales", y la Directiva 2012/29/UE del Parlamento Europeo y del Consejo de 25 de octubre de 2012, por la que se establecen normas mínimas sobre los derechos, el apoyo y la protección de las víctimas de delitos, que sustituye a la anterior, han marcado y marcan una serie de pautas para la implantación de la justicia restaurativa en los países integrantes de la Unión Europea.

La mediación en el ámbito penal, precisamente por las características del modelo procesal anglosajón ha tenido su mejor acogida en el Reino Unido. Estados como Bélgica, Francia, Portugal o Italia, han desarrollado la mediación penal mediante leyes específicas; otros como Alemania, han establecido un modelo de compensación autorvíctima con repercusiones en la pena, y otros, como en España, lo han recogido en sus 
leyes penales: Ley Orgánica 5/2000 reguladora de la responsabilidad penal de los menores, y la LO 1/2015 de reforma del Código Penal en sede de ejecución de la pena, así como las referencias a los procesos restaurativos dentro del Estatuto de la Víctima, introducido por la Ley 4/2015 de 27 de Abril. Otros Estados como Portugal y España excluyen por completo la violencia de genero de las materias susceptibles de ser sometidas al procedimiento de mediación ${ }^{19}$.

\section{EL ESTATUTO DE LA VÍCTIMA}

La Ley 4/2015, de 27 de Abril, conocida como Estatuto de la Víctima, y desarrollada reglamentariamente por el RD1109/2015, de 11 de diciembre, pretende regular los derechos, protección, información, atención, asistencia, apoyo y participación activa en el proceso de quienes hayan sido víctimas en la comisión de delitos $^{20}$. Su redacción obedece a las exigencias de la transposición de la Directiva Europea de 2012/29/UE.

El Estatuto trata de ofrecer una respuesta integral a la víctima, de ahí que se contemple la intervención de distintos profesionales para darleapoyo y tratamiento y de cabida a los distintos operadores jurídicos que tienen cabida en el proceso ${ }^{21}$. De ello resulta que no solo están implicados el Poder Judicial y las Administraciones Públicas sino también toda la sociedad, dando participación a los colectivos sociales y a las personas que en el ejercicio de sus funciones o cargos profesionales que tengan contacto con las víctimas ${ }^{22}$.

19. Página del Portal Europeo en el ámbito de Legislación Europea sobre la mujer: Artículo 44.5 de la LO 1/2004. de 28 de Diciembre, ya citada en el caso de España. Disponible en:https://ejustice.europa.eu/content_gender_equality-312-es.do.

${ }^{20}$ PINTOS PÉREZ,J. A., Aspectos constitucionales y procesales del estatuto de la víctima del delito y su relación con la problemática de la violencia de género en González-Ares Coordinador. Mujer, política e igualdad, Valencia, Editorial Tiran Lo Blanch, 2017, p. 343 y ss.

${ }^{21}$ En relación con los operadores jurídicos, no solo están implicados el Poder Judicial, las Administraciones Públicas, el Ministerio de Justicia, Sanidad y Servicios Sociales contando con la implicación privada que fomenta programas de ayudas a las victimas para su recuperación y reinserción en la sociedad.

${ }^{22}$ Vid. Preámbulo de la Ley 4/2015, de 27 de abril, por lo que se aprueba el Estatuto Jurídico de la Víctima del delito. 
Tanto en el ámbito internacional como nacional se ha destacado la necesidad de restablecer un concepto general de víctima y un catálogo de derechos procesales y extraprocesales que se le reconozcan como tal y, paralelamente, se han dispuesto tutelas más puntuales por los casos de «víctimas con especiales necesidades o con especial vulnerabilidad». Como afirma el mismo Estatuto, «los antecedentes y fundamentos remotos del presente Estatuto de la víctima del delito se encuentran en la Decisión Marco 2001/220/JAI del Consejo, de 15 de marzo de 2001, relativa al estatuto de la víctima en el proceso penal [...] El grado de cumplimiento de dicha Decisión Marco fue objeto del Informe de la Comisión Europea de abril de 2009, que puso de relieve que ningún Estado miembro había aprobado un texto legal único que recogiera, sistemáticamente, los derechos de la víctima y destacó la necesidad de un desarrollo general y efectivo de algunos aspectos del mencionado Estatuto». Con la aprobación de la Directiva 2012/29/UE del Parlamento Europeo y del Consejo, de 25 de octubre de 2012, que sustituye la Decisión Marco 2001/220/JAI del Consejo, procede transponer al derecho interno no sólo el contenido de la Decisión marco del 2001, sino las cuestiones que destacan en el Informe del 2009 y los nuevos derechos y exigencias que recoge la nueva Directiva.

El artículo 2 del Estatuto, al establecer el ámbito subjetivo de aplicación, redefine y amplía el concepto de víctima de la siguiente manera:

“a) Como víctima directa, a toda persona física que haya sufrido un daño o perjuicio sobre su propia persona o patrimonio, en especial lesiones físicas o psíquicas, daños emocionales o perjuicios económicos directamente causados por la comisión de un delito.

b) Como víctima indirecta, en los casos de muerte o desaparición de una persona que haya sido causada directamente por un delito, salvo que se tratare de los responsables de los hechos:

1. A su cónyuge no separado legalmente o de hecho y a los hijos de la víctima o del cónyuge no separado legalmente o de hecho que en el momento de la muerte o desaparición de la víctima convivieran con ellos; a la persona que hasta el momento de la muerte o desaparición hubiera estado unida a ella por una análoga relación de 
afectividad y a los hijos de ésta que en el momento de la muerte o desaparición de la víctima convivieran con ella; a sus progenitores y parientes en línea recta o colateral dentro del tercer grado que se encontraren bajo su guarda y a las personas sujetas a su tutela o curatela o que se encontraren bajo su acogimiento familiar.

2. ${ }^{\circ}$ En caso de no existir los anteriores, a los demás parientes en línea recta y a sus hermanos, con preferencia, entre ellos, del que ostentara la representación legal de la víctima.

Las disposiciones de esta Ley no serán aplicables a terceros que hubieran sufrido perjuicios derivados del delito."

Si este concepto general de víctima la trasladamos al ámbito de la víctima de violencia de género $^{23}$, ésta no es solamente la persona que de manera directa padece la violencia, sino, todos aquellos que de manera indirecta sufren también esa violencia y seven afectadas por la situación. Por tanto, la Ley dirige su protección, en lo que a violencia de género/ doméstica se refiere, a la persona que directamente sufre por ella en el seno de una familia o unidad familiar, normalmente serán los hijos menores.

Como ya se dijo, la ley, al buscar una solución integral va a facilitar los medios que son necesarios para proteger los derechos básicos desde los primeros momentos en que se produce una situación de violencia. Así, regula y facilita el acceso a los servicios de apoyo, que se van prestar con el nacimiento de la situación, centrándose éstos en: la acogida inicial, orientación e información y las medidas adecuadas de protección, como pueden ser la orden de alejamiento entre otras sin perjuicio de apoyos específicos para

\footnotetext{
${ }^{23}$ Consejo General del Poder Judicial. (Página web). Disponible en: http://www.poderjudicial.es/cgpj/es/Temas/Violencia-domestica-y-de-genero/Legislacion-yjurisprudencia/Legislacion/. Normas: Real Decreto 1109/2015, de 11 de diciembre, por el que se desarrolla la Ley 4/2015, de 27 de abril, del Estatuto de la víctima del delito, y se regulan las Oficinas de Asistencia a la Víctimas del Delito. Ley Orgánica 8/2015, de 22 de julio, de modificación del sistema de protección a la infancia y a la adolescencia. Ley 23/2014, de 20 de noviembre, de reconocimiento mutuo de resoluciones penales en la Unión Europea. Ley Orgánica 7/2014, de 12 de noviembre, sobre intercambio de información de antecedentes penales y consideración de resolución judiciales penales en la Unión Europea. Ley Orgánica 1/2014, de 28 de diciembre, de Medidas de Protección integral contra la Violencia de Género. Ley 27/2003, de 31 de julio, reguladora de la Orden de protección de las víctimas de la violencia domestica. Directiva 2012/29/UE del Parlamento Europeo y del Consejo de 25 de octubre de 2012 por la que se establecen normas mínimas sobre los derechos, el apoyo y la protección de las víctimas de delitos, y por la que se sustituye la Decisión marco 2001/220 JAI del Consejo. Directiva 2011/99/UE del Parlamento Europa sobre prevención y lucha contra las mujeres y la violencia doméstica.
} 
cada víctima, según aconseje su evaluación individual y para ciertas categorías de víctimas de especial vulnerabilidad.

Igualmente, a los menores que se encuentren en un entorno de violencia de género o violencia doméstica, se les garantiza el acceso a los servicios de asistencia y apoyo, así como la adopción de medidas de protección, con el objetivo de facilitar su recuperación integral ${ }^{24}$. La finalidad del Estatuto es la coordinación y sistematización de todos los derechos y la protección a las víctimas desde la primera incidencia, (que puede comenzar con un aviso a la policía), hasta la finalización del proceso. En definitiva, se trata proporcionar el asesoramiento y apoyo que necesitan las víctimas. ${ }^{25}$

Generalmente, el Estado de Derecho abarca un complejo de libertades negativas que reconoce al ciudadano, absteniéndose de ejercer una coerción que afecte a los Derechos Fundamentales y a la dignidad de la persona en relación con su integridad física y el desarrollo de su esfera moral y económica. Por esa razón estamos acostumbrados a pensar en las garantías del proceso penal como un instrumento en favor del acusado de un delito, el cual se supone sea el único en poder padecer un sufrimiento a causa del complicado mecanismo que se activa desde que el hecho denunciado se convierte en objeto de investigación por parte de la autoridad.

Sin embargo, aun cuando no existe un acusado, ya existe una persona cuya dignidad, libertad personal, intimidad y más Derechos Fundamentales se ven afectados en todo momento, es decir, la víctima del delito. Además, mientras la vulneración de los derechos del acusado es sólo potencial, la situación de vulnerabilidad de la víctima es anterior y perdura en el tiempo, de tal manera que se habla de victimización primaria, secundaria y terciaria. «La victimización primaria refleja la experiencia individual de la víctima y de las diversas consecuencias perjudiciales primarias producidas por el delito, de índole física, económica, psicológica o social» ${ }^{26}$.

\footnotetext{
${ }^{24}$ Vid. El preámbulo de la ley 4/2015, de 27 de abril, por lo que se aprueba el Estatuto Jurídico de la Víctima del delito. Párrafo IV.

${ }^{25}$ Educando en igualdad, (Página web). Disponible en: : http://www.educandoenigualdad.com/2016/03/01/estatuto-victima-violencia-de-genero-guia-practica/.

${ }^{26}$ NAVARRO OLASAGASTI N., Aspectos psicológicos básicos de la atención a las víctimas por parte de los cuerpos de seguridad, (Página web), p. 16. Disponible en http://www.osce.org/es/odihr/26723?download=true.
} 
La victimización secundaria y terciaria son un sufrimiento añadido: en primer lugar debido al revivir el episodio de violencia, cuando la intervención de las instituciones y de los profesionales encargados no es apropiada y supone una importante fuente de estrés que lleva a una progresiva desconfianza respecto del sistema de justicia; en segundo lugar, cuando el contexto social y los medios de comunicación "etiquetan" la persona como víctima ${ }^{27}$.

Como ya se dijo, el Estatuto establece la titularidad de los derechos en él contenidos. Por ello distingue dos tipos de víctimas: una directa, que haya sufrido personalmente un daño o perjuicio físico, económico o emocional causado por la comisión de un delito; y otra $\mathrm{u}$ otras indirectas, que se encuentran en su entorno familiar $^{28}$.

Pero, también, el Estatuto va a fijar la extensión de la tutela en él prevista, estableciendo que «la protección y el apoyo a la víctima no es sólo procesal, ni depende de su posición en un proceso, sino que cobra una dimensión extraprocesal» ${ }^{29}$ esta dimensión se extiende a la coordinación de todos los derechos expuestos anteriormente ${ }^{30}$.

Sin duda la accesibilidad en el lenguaje es imprescindible a la hora de poder ayudar y tratar a la víctima. El lenguaje jurídico es un lenguaje profesional que utiliza tecnicismos, y también es frio para poder utilizarse en una situación envuelta en tintes de alto contenido emocional por la que se suele necesitar ayuda o tratamiento

\footnotetext{
${ }^{27}$ NAVARRO OLASAGASTI N., op. cit., pp. 16-17.
}

${ }^{28}$ Como recoge el artículo 2 del Estatuto, se puede distinguir entre las personas que sufren directamente en su propia persona o patrimonio una lesión debida al hecho delictivo y otras personas que se ven afectadas de manera indirecta, perteneciendo al entorno familiar y afectivo de la víctima directa, de la cual el delito haya producido la desaparición o muerte, salvo - como hace notar el mismo artículo - en el caso en qué la persona que goza de tal vínculo con víctima sea la misma responsable del hecho.

${ }^{29} \mathrm{El}$ apoyo a la víctima es tanto material como moral y se desarrolla atendiendo a sus necesidades especiales, durante todo un proceso de orientación, información y protección, así como destaca IGLESIAS CANLE, I,op cit, p. 73.

${ }^{30}$ Cabe la necesidad de recordar que el catálogo de derechos contenido en este Estatuto es muy amplio e incluye - entre otros - el derecho a la información, asistencia y atención, a recibir un trato respetuoso, profesional, individualizado y no discriminatorio. Cuanto a la duración de estos derechos reunidos en el articulo 3 -, ella va desde el «primer contacto con las autoridades o funcionarios, durante la actuación de los servicios de asistencia y apoyo a las víctimas y de justicia restaurativa, a lo largo de todo el proceso penal y por un período de tiempo adecuado después de su conclusión, con independencia de que se conozca o no la identidad del infractor y del resultado del proceso». 
psicológico $^{31}$. Por lo que se debe dotar a las instituciones de protocolos de actuación con el fin de conseguir la adecuada llevanza de la situación ${ }^{32}$.

«La adopción de medidas y el acceso a ciertos servicios vienen precedidos de una evaluación individualizada de la víctima, para determinar sus necesidades de protección específica y de eventuales medidas especiales - atendiendo al carácter de la persona, al delito y sus circunstancias, a la entidad del daño y su gravedad o a la vulnerabilidad de la víctima -. Dichas medidas han de actualizarse con arreglo al transcurso del proceso y a las circunstancias sobrevenidas [...] y buscan la efectividad frente a represalias, intimidación, victimización secundaria, daños psíquicos o agresiones a la dignidad durante los interrogatorios y declaraciones como testigo, e incluyen desde las medidas de protección física hasta otras, como el uso de salas separadas en los Tribunales, para evitar contacto de la víctima con el infractor y cualesquiera otras, bajo discrecionalidad judicial, que exijan las circunstancias» ${ }^{33}$.

Con las modificaciones introducidas por el Estatuto de la Víctima, las víctimas de violencia de género ven ampliada su asistencia y su protección, su cónyuge no tendrá la consideración de víctima indirecta cuando sea el autor de los hechos, se destacan como víctimas a los menores que se encuentran en un entorno de violencia de género ytambién se dispone la realización de una evaluación individual de las víctimas para determinar sus necesidades especiales de protección. ${ }^{34}$

31 El artículo 5 del Estatuto destaca como en este sentido sea fundamental evitar retrasos innecesarios, adaptar la información a las circunstancias y condiciones personales, a la naturaleza del delito y a la entidad del perjuicio sufrido, para orientar la víctima sobre las medidas de asistencia y apoyo disponibles, sean médicas, psicológicas o materiales, el derecho a denunciar - y a participar en el proceso penal y a intervenir, siempre y cuando que la ley lo prevea, en la ejecución de la pena - el proceso para obtener asesoramiento y defensa jurídica.

${ }^{32}$ Los artículos 20 y 21, con el fin de evitar situaciones de estrés a la víctima, recomiendan - por ejemplo - procurar que no haya retrasos injustificados o el contacto entre la víctima y el acusado, dotar los varios operadores de la justicia y sociales de formación técnica - también para un mejor desarrollo de capacidades empáticas -, reducir el número de declaraciones y reconocimientos médicos al mínimo necesario.

${ }^{33}$ Articulo 23 y siguientes del Estatuto.

${ }^{34}$ Ministerio de Sanidad, Servicios Sociales e Igualdad., (Página web). Disponible en: http://www.msssi.gob.es/ca/ssi/violenciaGenero/QueHacer/ordenProteccion/home.htm. La orden de protección unifica los distintos instrumentos de protección a la víctima previstos por el ordenamiento jurídico y le confiere un estatuto integral de protección.En los casos en que, existiendo indicios fundados de la comisión de un delito o falta contra la vida, integridad física o moral, libertad sexual, libertad o seguridad de una mujer (por parte de un hombre que sea o haya sido su cónyuge o que esté o haya estado 
Por último, se debe reseñar que, si bien en el Estatuto se contemplan medidas restaurativas como alternativa al proceso, éstas, con carácter general están muy limitadas, y en el caso concreto de la violencia de género/doméstica están concretamente excluidas. Así el artículo 15 establece que:

“1. Las víctimas podrán acceder a servicios de justicia restaurativa, en los términos que reglamentariamente se determinen, con la finalidad de obtener una adecuada reparación material y moral de los perjuicios derivados del delito, cuando se cumplan los siguientes requisitos:

a) El infractor haya reconocido los hechos esenciales de los que deriva su responsabilidad;

b) La víctima haya prestado su consentimiento, después de haber recibido información exhaustiva e imparcial sobre su contenido, sus posibles resultados y los procedimientos existentes para hacer efectivo su cumplimiento;

c) El infractor haya prestado su consentimiento;

d) El procedimiento de mediación no entrañe un riesgo para la seguridad de la víctima, ni exista el peligro de que su desarrollo pueda causar nuevos perjuicios materiales o morales para la víctima; y

e) No esté prohibida por la ley para el delito cometido.

2. Los debates desarrollados dentro del procedimiento de mediación serán confidenciales y no podrán ser difundidos sin el consentimiento de ambas partes. Los mediadores y otros profesionales que participen en el procedimiento de mediación, estarán sujetos a secreto profesional con relación a los hechos y manifestaciones de que hubieran tenido conocimiento en el ejercicio de su función.

ligado a ella por relaciones similares de afectividad, aun sin convivencia), resulta una situación objetiva de riesgo para la víctima que requiere la adopción de alguna medida de protección. 
3. La víctima y el infractor podrán revocar su consentimiento para participar en el procedimiento de mediación en cualquier momento."

Indudablemente, el artículo 15.1 e) se refiere al artículo 44.5 de Ley Orgánica 1/2004, de 28 de diciembre, de Medidas de Protección Integral contra la Violencia de Género, que prohíbe la mediación.

\section{MEDIACIÓN EN CASOS DE VIOLENCIA DE GÉNERO: VENTAJAS E INCONVENIENTES.}

Como ya se dijo, la mediación es un método de justicia restaurativo y autocompositivo $^{35}$ cuyo objetivo es resolver el conflicto entre las partes mediante un acuerdo.

¿Realmente la utilización del procedimiento de mediación es beneficiosa para las partes que se encuentran en un proceso de violencia de género? La violencia de género es algo más que un conflicto entre las partes, ya que ataca a bienes jurídicos de especial protección. Por otra parte, es sabido que uno de los principios básicos de la mediación es la igualdad entre las citadas partes ${ }^{36}$; bien, pues en los procesos de violencia de género, difícilmente se va a dar ni tan siquiera una relativa igualdad, ya que la raíz del problema es la desigualdad por razón de género, además de que la víctima, siempre se va a encontrar en una situación psicológica de inferioridad ${ }^{37}$. Es decir, con

${ }^{35}$ FERNÁNDEZ LÓPEZ, M. A.: La mediación en procesos por violencia de género, Primera Edición, Navarra, 2015, Editorial Thomson Reuters, p. 47 y ss.

${ }^{36}$ IGLESIAS CANLE, I., C.,La Tutela Judicial en el ámbito de la violencia de género: la promoción real del principio de igualdad, en Violencia de género: perspectiva jurídica y psicosocial.Iglesias Canle, I. C. y Lameiras Fernández, M., Coordinadoras, Valencia, Editorial Tirant Lo Blanch, 2009, p. 95 y ss.

${ }^{37}$ Psicoterapeutas.com, (Página web). Disponible http://www.psicoterapeutas.com/violencia_de_genero.html. "El síndrome de la mujer maltratada, definido por Walker y Dutton se define como una adaptación a la situación aversiva caracterizada por el incremento de la habilidad de la persona para afrontar los estímulos adversos y minimizar el dolor, además de presentar distorsiones cognitivas, como la minimización, negación o disociación; por el cambio en la forma de verse a sí mismas, a los demás y al mundo. También pueden desarrollar los síntomas del trastorno de estrés postraumático, sentimientos depresivos, de rabia, baja autoestima, culpa 
frecuencia la víctima de violencia de género se encuentra en una situación tal, que muy difícilmente puede llegar a concluir acuerdo alguno sobre una situación que probablemente le haya causado un trauma. En tales condiciones hablar de justicia "autocompositiva ${ }^{38 "}$ para reconducir una situación se aleja mucho de la realidad porque no hay nada que recomponer o restaurar, aunque si cabe buscar los medios más eficaces para poner fin a una situación insostenible lo más rápidamente posible y con el menor daño para la víctima. Ahí, tal vez fuera posible hablar de mediación.

Quizá se den situaciones en que las dos personas dentro de una relación lleven una convivencia violenta, con agresiones mutuas siendo ambas realmente las víctimas y las dos están afectadas, por lo que respetando íntegramente el contenido de la Ley cabría la mediación con carácter preventivo, otra cosa es que resultase beneficiosa a largo plazo. Desde mi experiencia profesional la idoneidad de la mediación en relación con su aplicación los casos violencia de género se hace muy difícil. Como ya dijimos choca con los principios esenciales de toda mediación, libertad y voluntariedad y se torna prácticamente imposible ${ }^{39}$.

No obstante, existe una doble posición doctrinal al respecto, partidarios y detractores de la mediación en casos de violencia de género con sus correspondientes argumentos, cuestión que configurará el objeto central de nuestro sucinto trabajo y nos permitirá dilucidar si, en efecto, la misma resultaría o no factible y en qué supuestos.

La Ley de Enjuiciamiento Criminal permite la posibilidad de conformarse en los juicios rápidos, siempre que la acusación particular y el fiscal estén de acuerdo, en este

y rencor; y suelen presentar problemas somáticos, disfunciones sexuales, conductas adictivas y dificultades en sus relaciones personales. Enrique Echeburúa y Paz del Corral equiparan estos efectos al trastorno de estrés postraumático, cuyos síntomas y características, sin duda, aparecen en algunas de estas mujeres: re-experimentación del suceso traumático, evitación de situaciones asociadas al maltrato y aumento de la activación. Estas mujeres tienen dificultades para dormir con pesadillas en las que reviven lo pasado, están continuamente alerta, hiper vigilantes, irritables y con problemas de concentración. Además, el alto nivel de ansiedad genera problemas de salud y alteraciones psicosomáticas, y pueden aparecer problemas depresivos importantes".

${ }^{38}$ FERNÁNDEZ LÓPEZ, M. A.: La mediación en procesos por violencia de género, Primera Edición. Navarra, 2015, Editorial Thomson Reuters, p. 47 y ss.

39 Independientemente de los beneficios, o no, que pueda aportar la mediación se encuentra prohibida por el artículo 44 de LO 1/2004. CLEMENTE DÍAZ, C., Violencia de Género y medios de comunicación en Violencia de género: perspectiva jurídica y psicosocial.Iglesias Canle, I. C. y Lameiras Fernández, M., Coordinadoras. Valencia, Editorial Tirant Lo Blanch, 2009. p. 200 y ss. 
momento cabe una labor de mediación que prácticamente no se conoce y la hacen los abogados y el físcal, no los mediadores. Es una mediación de la que no se habla y no se hace con las garantías que debe tener la mediación. Al juez/a, ya se le da la sentencia.

Un ejemplo práctico es la sentencia que comenta un compañero, recaída en un asunto de violencia de género/ doméstica llevado por él, a raíz de un cruce de denuncias que dio lugar a una situación enconada entre los cónyuges, padres de dos niños de corta edad. Esta pareja se dejó aconsejar por los respectivos letrados, que actuaron con talante mediador, y un fiscal que no se opuso ya que se trataba de un hecho que no era grave. El resultado fue que se llegó a un acuerdo en el que todos salieron beneficiados. En opinión de este compañero, basada en su experiencia, y en la mía en otro caso similar, la mediación sí resultó beneficiosa porque logró zanjar el asunto, pero tal vez un par de casos no se puedan elevar a categoría general. A veces, las denuncias se hacen en un momento de exaltación, fruto de un acalorado enfrentamiento entre las partes, sin ser conocedores de las consecuencias que dichas denuncias pueden acarrear a la unidad familiar y en esos supuestos, si tiene cabida la mediación, si se trata de hechos muy leves y siempre que la mediación se haga bajo la dirección letrada. Con todo, creo que estos mecanismos no ofrecentodas las garantías necesarias que para las partes que consagra la mediación ${ }^{40}$.

Los resultados recogidos por el Consejo General del Poder Judicial no son satisfactorios, ya que considero que la solución no se encuentra en habilitar un espacio para los procesos de mediación, sino más bien en buscar otros medios, tales como programas familiares de ayuda o de reeducación socio familiar, pero sin considerar factible el proceso de Mediación, puesto que no se da el espacio idóneo al mediador ni a las partes para realizar el proceso, además de no existir el necesario equilibrio entre las partes.

La mediación se está valorando como posible instrumento en el que, de una parte, la victima pueda ser oída y exprese qué daño le ha producido el delito y cuáles

40 ÁLVAREZ BUJAN, Ma V.,La mediación en los casos de violencia de género ¿es posible?, en Roles de xénero nun mundo globalizado. XII Xornada Universitaria Galega en xénero. López Díaz A. J., González Penín A. y Aguayo Lorenzo E., Coordinadores. A Coruña, Ed. Universidade da Coruña, 2014, p. 255 y ss. 
son sus necesidades a satisfacer; y de otra, que el autor del delito se responsabilice de sus actos.

En ella, una parte neutral, con conocimientos adecuados y formación específica ayuda a la víctima y victimario a comprender el origen del conflicto, sus causas, sus consecuencias y a elaborar acuerdos para la reparación del daño.

\section{CONSIDERACIÓN FINAL}

Si bien, es cierto que las estadísticas no son muy optimistas respecto a la erradicación de la violencia de género y de que su judicialización penal no está dando los resultados esperados, también lo es que deberían buscarse fórmulas alternativas que aportasen soluciones aplicables a un gran número de supuestos.

Pero, lo cierto es que, de ser aplicable la mediación a la violencia de género, ésta lo sería sólo sopesando caso por caso su idoneidad y siempre que los hechos punibles sean de una levedad tal que la víctima o victimas estén en condiciones de disponer libremente sobre su situación. Para lo cual, tal vez, fuese preceptivo un examen psicológico que valore su estado. Sin duda, creo que esto sólo se puede dar en casos muy contados, ya que la multi-victimización es la característica recurrente en la violencia de género, es decir, el padecimiento de reiterados episodios de violencia, como consecuencia de una larga convivencia con el agresor, (otra de las características singulares de este tipode víctimas) $)^{41}$. Y, a mayor abundamiento, la violencia se ejerce en un contexto muy concreto, en la vivienda familiar, por parte de un victimario con el que la víctima mantiene un vínculo afectivo muy fuerte, y a menudo su grave situación empeora como consecuencia de la denominada victimización secundaria. Esta consiste en una mala praxis a la hora de proteger a la víctima, que acude al sistema para que la defienda, y éste se ve incapaz de protegerla adecuada e inmediatamente ya que los

${ }^{41}$ Vid. al respecto: ECHEBURÚA, E./ AMOR, P.J./ DE CORRAL, P., Mujeres maltratadas en convivencia prolongada con el agresor: variables relevantes, en Acción psicológica, 2, 2002,p. 136: "Un fenómeno controvertido en el ámbito del maltrato doméstico se refiere a la permanencia de la víctima en convivencia prolongada con el agresor. Este hecho no supone una elección fruto exclusivamente del libre albedrío de la mujer. Es decir, existen multitud de condicionantes socio económicos, emocionales y psicopatológicos que influyen en la continuidad en la relación de maltrato". 
instrumentos proporcionados por la administración al efecto no son los adecuados, o ni siquiera existen. Hablamos de las casas de acogida, por ejemplo, en las que la propia mujer se siente sancionada por mor de la privación de libertad en su propia vida cotidiana $^{42}$.

Ni que decir tiene que, el procedimiento de mediación en estos casos debería ser conducido por un mediador muy cualificado y especializado en la materia; y aún, quedaría por resolver cómo se va a garantizar el cumplimiento del acuerdo por parte del victimario, y la resocialización del mismo ${ }^{43}$.

La conclusión es evidente: no cabe generalizar y por lo tanto, no se puede poner en marcha un gran sistema o engranaje para una casuística muy amplia que vuelva la mediación ineficaz, con el consiguiente peligro que puede entrañar para la víctima, pero no es menos cierto que a pesar de la prohibición legal podemos reflexionar sobre una posible mediación totalmente regulada y dirigida a casos muy específicos y únicamente como proyecto piloto experimental ${ }^{44}$.

${ }^{42}$ CALLE FERNÁNDEZ, S., Consideracionessobrelavictimización secundaria en la atención social a las víctimas de la violencia de género, en Portularia: Revista de Trabajo Social, 4, 2004, p. 65: "Con respecto a los recursos de acogida queremos señalar que la mayoría de las mujeres afectadas los desestiman, y que en muchas ocasiones son percibidos como una sanción contra ellas. Por otro lado, plantean la paradoja de trabajar con la finalidad de incrementar la autonomía personal desde un espacio donde, necesariamente, están regulados múltiples aspectos de la vida cotidiana”.

${ }^{43}$ CASTILlEJO MANZANARES, R./ TORRADO TARRÍO, C./ALONSO SALGADO, C., Mediación en violencia de género, en Revista de Mediación, 4, 7, 2011, p. 41, en donde señalan las carencias en el tratamiento del victimario: "El proceso penal en su configuración actual genera más sufrimiento personal en el victimario, que valores reeducativos, por lo tanto no sólo se dificulta su reinserción, sino que también se incrementan las probabilidades de reincidencia".

${ }^{44}$ Vid. al respecto, VALL RIUS, A./ GUILLAMAT RUBIO A., Mediación y violencia de género, una respuesta útil en los casos de archivo de la causa penal, en Revista de Mediación, 4, 7, 2011, p. 21, en donde se plantea las siguientes cuestiones: “¿Sería conveniente estudiar la posibilidad de aplicar nuevos modelos de intervención en el abordaje de estas situaciones? ¿Cabe plantearse si la mediación podría llegar a ser, entre otros, uno de los nuevos recursos adecuados para la gestión de algunos de estos casos? ¿Podría

la mediación actuar como instrumento de prevención, disponible en la detección de los primeros síntomas? Posiblemente, la mediación no sea aplicable en una mayoría de estos supuestos, ¿pero resulta útil negar siempre y de forma sistemática, a las partes y por tanto a la propia mujer, esta posibilidad, cuando podría significar una respuesta positiva y útil en algunas ocasiones? ¿Si la mediación ha de ser una opción consciente y plenamente voluntaria, escogida libremente por ambas partes, debe negárseles esta posibilidad, cuando se comprueba que esa libertad plena y consciente existe en el supuesto concreto? ¿El afán protector indiscriminado, podría ceder ante una decisión plenamente libre, consciente e informada por parte de la mujer?". 
En la actualidad, nos enfrentamos en España a esta dolorosa realidad, en la que el sistema judicial no dispone de un método eficaz resolutivo para estos casos, y además dificulta la situación de la víctima ${ }^{45}$, sin pretenderlo. Por otro lado, la situación del victimario, que el sistema judicial debe procurar reinsertar en la sociedad, no resulta fácil, obteniendo un resultado global precario en el tema de violencia de género.

La prohibición legal, que comparto, se impuso con el objetivo claro de evitar un desequilibrio en la mediación en el caso de la violencia contra la mujer. Dicho esto, los resultados en la justicia penal no son en absoluto positivos, por lo que el legislador debe reflexionar sobre nuevos métodos de composición de las relaciones familiares.

45 BRAVO BOSCH, M. J./ IGLESIAS CANLE, I. C., Mujer e igualdad desde el derecho romano hasta la actualidad: especial referencia al ordenamiento jurídico español, en Mujer, política e igualdad. De las palabras a los hechos, GONZÁLEZ ARES, J.A., (Coord.), Valencia, Editorial Tirant Lo Blanch, 2017, p. 73, en donde señalan, con respecto a la Ley 4/2015, de 27 de abril, del Estatuto de la víctima del delito, la necesaria visibilización de los menores como víctimas cuando se encuentran en un entorno de violencia de género o violencia doméstica: "Para garantizarles el acceso a los servicios de asistencia y apoyo, así como la adopción de medidas de protección, con el objetivo de facilitar su recuperación integral”. 


\section{BIBLIOGRAFÍA}

Abogacía Española, El Consejo de Ministros ha aprobado el Real Decreto-leyde medidas urgentes para el desarrollo del Pacto de Estado contra la Violencia de Género, que modifica la Ley de Bases del Régimen Local, la Ley de Medidas de Protección Integral contra la Violencia de Género y el Código Civil. (pägina web). Disponible en: https://www.abogacia.es/2018/08/06/el-gobierno-aprueba-el-realdecreto-ley-para-desarrollar-el-pacto-de-estado-contra-la-violencia-de-genero/.

ALCÁZAR CÓRCOLES, M.A./ GÓMEZ-JARABO, G., Aspectos psicológicos de la violencia de género. Una propuesta de intervención, en Psicopatología Clínica, Legal y Forense, Vol.1, n 2, 2001.

ÁLVAREZ BUJAN, M ${ }^{\mathrm{a}} \mathrm{V}$., La mediación en los casos de violencia de género ¿es posible?, en Roles de xénero nun mundo globalizado. XII Xornada Universitaria Galega en xénero. LÓPEZ DÍAZ A. J., GONZÁLEZ PENÍN A. y AGUAYO LORENZO E., Coordinadores. A Coruña, Editorrial Universidade da Coruña, 2014.

BRAVO BOSCH, M. J., Sobre el nuevo real decreto-ley 5/2012 y la mediación familiar, en Revista General de Derecho Romano 18, www. iustel.com, 2012.

BRAVO BOSCH, M. J., La mediación familiar en el estado de las autonomías, en La mediación en las controversias civiles y mercantiles, IGLESIAS CANLE, I. (dir.), Valencia, Editorial Tirant lo Blanch,2014.

BRAVO BOSCH, M. J./ IGLESIAS CANLE, I. C., Mujer e igualdad desde el derecho romano hasta la actualidad: especial referencia al ordenamiento jurídico español, en Mujer, política e igualdad. De las palabras a los hechos, GONZÁLEZ ARES, J.A., (Coord.), Valencia, Editorial Tirant Lo Blanch, 2017.

CALLE FERNÁNDEZ, S., Consideracionessobrelavictimización secundaria en la atención social a las víctimas de la violencia de género, en Portularia: Revista de Trabajo Social, 4, 2004.

CASTILLEJO MANZANARES, R./ TORRADO TARRÍO, C./ALONSO SALGADO, C., Mediación en violencia de género, en Revista de Mediación, 4, 7, 2011,

CLEMENTE DÍAZ, C., Violencia de Género y medios de comunicación, en Violencia de género: perspectiva jurídica y psicosocial. IGLESIAS CANLE, I., C. y LAMEIRAS FERNÁNDEZ, M., Coordinadoras. Valencia, Editorial Tirant lo Blanch, 2009.

Consejo General del Poder Judicial, (Página web), Observatorio contra la violencia doméstica y de género. Disponible en http://www.poderjudicial.es/cgpj/es/Poder-Judicial/En-Portada/En-el-tercer-trimestredel-ano-aumentaron-las-denuncias-por-violencia-de-genero-y-las-condenas-a-losmaltratadores. 
Consejo General del Poder Judicial, (Página web). Disponible en: http://www.poderjudicial.es/cgpj/es/Temas/Violencia-domestica-y-degenero/Legislacion-y-jurisprudencia/Legislacion/.

ECHEBURÚA, E./ AMOR, P. J./ DE CORRAL, P., Mujeres maltratadas en convivencia prolongada con el agresor: variables relevantes, en Acción psicológica 2, 2002.

Educando en igualdad, (Página web). Disponible en: : http://www.educandoenigualdad.com/2016/03/01/estatuto-victima-violencia-de-generoguia-practica/.

ENGLE MERRY, S., Gender violence. A Cultural Perspective, West Sussex, 2009.

IGLESIAS CANLE, I., C. La Tutela Judicial en el ámbito de la violencia de género: la promoción real del principio de igualdad en Violencia de género: perspectiva jurídica y psicosocial.IGLESIAS CANLE, I., C. y LAMEIRAS FERNÁNDEZ, M., Coordinadoras. Valencia, Editorial Tirant lo Blanch, 2009.

IGLESIAS CANLE, I.C., El principio de igualdad desde un enfoque pluridisciplinar.GONZÁLEZ-ARES FERNÁNDEZ, J.A. y ÁLVAREZ BUJÁN M. V., Coordinadores.Valencia, Editorial Tirant lo Blanch, 2016.

FARALDO CABANAS, P., Razones para la introducción de la perspectiva de género en Derecho penal a través de la Ley Orgánica 1/2004, de 28 de diciembre, sobre medidas de protección integral contra la violencia de género,en Revista Penal, 17, 2006.

FERNÁNDEZ LÓPEZ, M. A.,La mediación en procesos por violencia de género, Primera Edición. Navarra, Editorial Thomson Reuters, 2015.

HÉRCULES DE SALÁS CARDEÑA, M.: La mediación como herramienta en determinados casos de violencia de género, en Documentos de Trabajo Social, n 52.

MARTÍN LUCAS, B., Violencia simbólica, violencia real: a cultura que nos agrede en Roles de xénero nun mundo globalizado. XII Xornada Universitaria Galega en xénero.LÓPEZ DÍAZ A. J., GONZÁLEZ PENÍN A. y AGUAYO LORENZO E., Coordinadores. A Coruña, Editorial Universidade da Coruña, 2014.

MAQUEDA ABRAU, M.L., La violencia de género entre el concepto jurídico y la realidad social, en Revista Electrónica de Ciencia Penal y Criminología, 08-02, 2006.

MATEO BUENO, F.,Opiniones prácticas de letrados a las que me suscribo. (Página web). Disponible en: file:///Volumes/ART\%20VG\%20MF/¿ES\%20POSIBLE\%20LA\%20MEDIACIÓN\%20 EN\%20MATERIA\%20DE\%20VIOLENCIA\%20DE\%20GÉNERO_\%20

$\% 20$ MATEOBUENO $\% 20 \bullet \% 20$ abogado $\% 20 \mathrm{y} \% 20$ mediador.htm. 
Naciones Unidas Derechos Humanos, Oficina del Alto ComisionadoResolución de la Asamblea General Resolución 48/104. Disponible en: http://www.ohchr.org/SP/ProfessionalInterest/Pages/ViolenceAgainstWomen.aspx.

NOYA FERREIRO, L., La protección de la mujer víctima de violencia de género en Galicia: regulación procesal, en Estudios penales y criminológicos, n 28, 2008.

Página del Portal Europeo en el ámbito de Legislación Europea sobre la mujer. (Página web). Disponible en:https://e-justice.europa.eu/content_gender_equality-312es.do.

PERAMATO MARTÍN, T., La violencia de Género e Intrafamiliar en el Derecho Penal Español en Violencia de género: perspectiva jurídica y psicosocial. IGLESIAS CANLE, I. C. y LAMEIRAS FERNÁNDEZ, M., Coordinadoras. Valencia, Editorial Tirant Lo Blanch, 2009.

Psicoterapeutas.com, (Página web). Disponible en: http://www.psicoterapeutas.com/violencia_de_genero.html

PLAZA VELASCO, M.,Sobre el concepto de violencia de género. Violencia simbólica, lenguaje, representación en Extravío. Revista Electrónica de Literatura Comparada, 2, 2007.

SÁENZ HERMIDA, A., Víctimas de violencia de género: reconocimiento y protección de sus derechos en Violencia de género. La violencia sexual a debate. IGLESIAS CANLE, I. C. y LAMEIRAS FERNÁNDEZ, M., Coordinadoras. Valencia, Editorial Tirant lo Blanch, 2011.

VALL RIUS, A./ GUILLAMAT RUBIO A., Mediación y violencia de género, una respuesta útil en los casos de archivo de la causa penal, en Revista de Mediación, 4, 7, 2011. 